\title{
Journal of Bacteriology and

\section{Nutritional Status and Prevalence of Intestinal Schistosomiasis among Al-majiri Population in Kawo District of Kaduna Metropolis, Kaduna State-Nigeria}

\author{
Mahmood Mohammed ${ }^{1}$, Philip Anthony Vantsawa ${ }^{1}$, Umar Yahaya Abdullahi ${ }^{1 *}$ and Muhammad Dauda Muktar ${ }^{2}$ \\ ${ }^{1}$ Nigerian Defence Academy, Kaduna, Kaduna State, Nigeria \\ ${ }^{2}$ Bayero University Kano, Kano state, Nigeria \\ *Corresponding author: Umar Yahaya Abdullahi, Nigerian Defence Academy, Kaduna, Kaduna State, Nigeria, Tel: +216 73221411 ; E-mail: \\ umaryahaya09@gmail.com
}

Received date: July 15, 2015; Accepted date: August 06 2015; Published date: August 11, 2015

Copyright: ( 2015 Mohammed et al. This is an open-access article distributed under the terms of the Creative Commons Attribution License, which permits unrestricted use, distribution, and reproduction in any medium, provided the original author and source are credited.

\begin{abstract}
A cross sectional study was carried out between July and November, 2014 to determine the nutritional status and prevalence of intestinal schistosomiasis due to Schistosoma mansoni among Al-Majiri population in Kawo District, Kaduna Metropolis of Kaduna state, Nigeria. Three hundred and sixty (360) samples were collected and analyzed by formol-ether concentration techniques. Information on their ages and water contact activities were obtained through KAP questionnaire while anthropometric measurements were used to determine the nutritional status of the participants. Result obtained showed an overall prevalence of $18.6 \%$ and a mean intensity of 40 eggs/gram of stool. Prevalence of Schistosoma mansoni was not significantly different $(p>0.05)$ among the age group. However, water contact activities significantly $(p<0.05)$ influenced the prevalence of $S$. mansoni. There was an inverse correlation between intestinal schistosomiasis and nutritional status of Al-majiri population surveyed ( $r=-0.99$ ). It is concluded that intestinal schistosomiasis is a significant health problem and a major cause of severe malnutrition among the population studied. To alleviate these problems, relevant government agencies and Non-Governmental Organization (NGOs) should embark on provision of potable water, adequate nutrition and regular mass literacy campaign on the need for improved personal hygiene.
\end{abstract}

Keywords: Al-Majiri; Intestinal schistosomiasis; Schistosoma mansoni; Nutritional status

\section{Background}

Almajiri is derived from an Arabic word "Almuhajirun" meaning emigrant in search of knowledge. In Nigeria, Almajiri are usually children aged between 3-13 yrs and sometimes older who left their homes mostly rural areas under the guidance of an adult to stay in major towns. The adult guardian who also serves as teacher is often unemployed and therefore depends on goodwill from well spirited individuals. Due to the large number of children usually attached to a teacher coupled with hard economic hardship due to lack of steady income, these children often live in an impoverished environment and are therefore exposed to various diseases that could have significant public health implications [1].

Of major importance is schistosomiaisis caused by Schistosoma mansoni, $S$. guineensis, $S$. intercalatum, $S$. japonicum and $S$. mekongi in different parts of the world [2]. Schistosomiasis is one of the most common parasitic infections in the world ranking second to malaria in terms of socio-economic and public health importance in many tropical and subtropical areas $[3,4]$. The disease is associated with agricultural, domestic, developmental and recreational activities which exposes human to cercaria infested water. Many fresh water snails such as Bulinus species serves as intermediate host.

It is estimated that over 207 million people are infected worldwide especially in poor communities with no access to safe drinking water and adequate sanitation while 700 million others are at risk [5]. Although the disease occurs in Africa, South America and Asia, 90\% of schistosomiaisis cases are found in sub-sahara Africa [2].
Among the species endemic in Nigeria, Schistosoma mansoni is responsible for the cases of intestinal schistosomiasis. The disease is characterized by anaemia, hepatomegaly, splenomegaly, cognitive dysfunction and delayed growth in children [6].

Due to lack of access to good water source coupled with absence of parental care, many Al-majiri uses available water sources such as streams and ponds for drinking, washing and bathing. These water bodies most often are contaminated with disease causing agents thus serving as source of infection to users.

In the past, several worm control campaigns by government and non-governmental agencies (NGO's) in Nigeria have always targeted children in public and private schools and completely neglecting the Al-majiri schools. This among other factors has undermined such campaign programmes as those infected among this segment of the society continuously seed the environment with infective stages of the parasite. However, for any control programme to be successful there is need for adequate information on the epidemiology of the diseases including the population at risk. The study was therefore aimed at ascertaining the nutritional status and the prevalence of intestinal schistosomiaisis among $\mathrm{Al}$-majiri population attending various $\mathrm{Al}$ majiri schools in Kawo district of Kaduna state, Nigeria considering their role in the epidemiology of many diseases some of which are of public health importance.

\section{Materials and Methods}

\section{Study area}

The study was conducted in kawo district of Kaduna metropolis, Kaduna State Nigeria. Kawo district comprises of the following 
Citation: Mohammed M, Vantsawa PA, Abdullahi UY, Muktar MD (2015) Nutritional Status and Prevalence of Intestinal Schistosomiasis among Al-majiri Population in Kawo District of Kaduna Metropolis, Kaduna State-Nigeria. J Bacteriol Parasitol 6: 237. doi: 10.4172/2155-9597.1000237

Page 2 of 5

settlements: Kawo, Rafinguza, Badarawa and Unguwan Dosa. The settlers are mostly civil servants, farmers and traders most of whom are from the Hausa tribe thus contributing immensely to the large population of Al-Majiri children in the area (Figure 1). Kaduna State is located in the northwest geopolitical zone of Nigeria and lies between $10^{\circ} 20^{\prime} \mathrm{N}$ and $10.33^{\circ} \mathrm{N}$ and latitude $7^{\circ} 45^{\prime} \mathrm{E}$ and $7.75^{\circ} \mathrm{E}$. The vegetation is characteristic of the Guinea savannah type with distinct wet and dry season. The state shares boarders with Katsina and Zamfara states to the North, Plateau and Bauchi states to the East, Nasarawa state and the Federal Capital Territory (FCT) to the South and Niger state to the West.

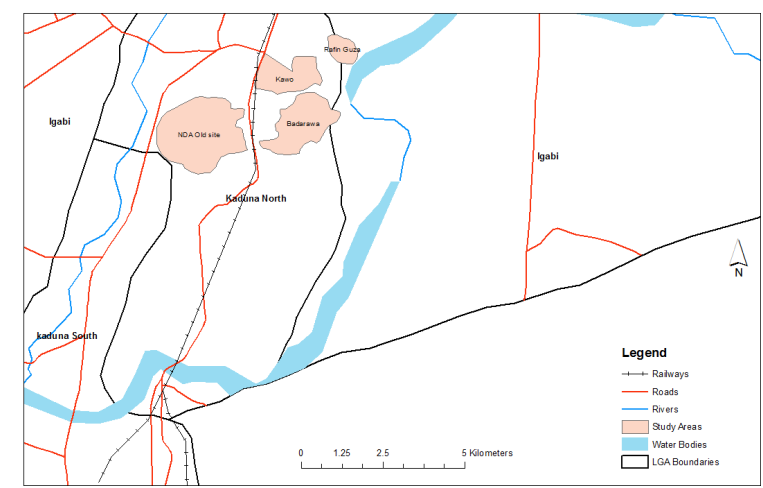

Figure 1: Sketch map of Kaduna state showing the study area.

\section{Sample population}

The study population was made up of children and adolescents whose parents have consented to their enrolment into the Al-majiri system of education and are totally under the care and guidance of the teacher.

Participants who were found to be staying with their parents were excluded from the study.

\section{Selection of almajiri schools}

Al- majiri schools were randomly selected within Kawo district in Kaduna metropolis, Kaduna State. During a pre-survey visit to the schools, participants and teachers of selected schools were enlightened on the importance of the study and the need for them to give samples and to respond to all the questions in the knowledge attitude and practice (KAP) questionnaire that would to be administered.

\section{Ethical clearance}

Ethical clearance was obtained from Kaduna State Ministry of Health using a written informed consent form that was signed by the teachers (malam) who legally stand as the guardian to all the participants while they are in the city.

\section{Sample size determination}

Sample size was determined based on the description for calculating sample size as follows [7]: $n=\frac{z 2 p q}{d 2}$ at $95 \%$ confident interval. Where $\mathrm{n}=$ sample size, $\mathrm{z}=$ standard normal deviation at $95 \%$ confident interval (1.96), $\mathrm{p}=$ prevalence from previous studies, $\mathrm{q}=1-\mathrm{p}, \mathrm{d}=$ tolerable error (0.05).

\section{Sample collection}

Three hundred and sixty fecal samples were collected from participants that were selected by systematic random sampling technique. Each of the participant was given a labeled clean dry screw capped container and wooden applicator, and guided on when and how to collect their fecal samples. Stool samples collected were transported on ice in thermo box to the Department of Biological Sciences laboratory, Nigerian Defence Academy, Kaduna for parasitological analysis.

Stool samples collected were processed using formol - ether concentration technique as described by Cheesbrough [8]. One gram ( $1 \mathrm{gm})$ of feces was suspended in $10 \mathrm{ml}$ of $10 \%$ formaldehyde solution and mixed thoroughly using a glass rod. The suspension was then passed through a funnel covered with a gauze pad into a centrifuge tube. To the filtrate, $3 \mathrm{ml}$ of ether was added and mixed thoroughly by shaking gently before centrifuging for $3 \mathrm{~min}$ at $4000 \mathrm{rpm}$. The supernatant was decanted and the sediment examined under light microscope at 10X and 40X objectives. Schistosome eggs seen were identified and counted as egg per gram (epg).

Anthropometric measurement such as height and weight were taken as described by WHO [9]. Digital floor scale was used to measure participant's weight; height was measured with a wall mounted stadiometer while nutritional status was based on Body Mass Index (BMI) for age $[10,11]$.

$$
\text { Where: } B M I=\frac{\text { Weight }(K g)}{\operatorname{Height}\left(m^{2}\right)}
$$

\section{Questionnaire administration}

Well-structured knowledge, attitude and practice (KAP) questionnaire was administered to each participant to obtain information such as age, hobby, perception (level of awareness of schistosomiasis) and water contact activities etc. Questionnaires were interpreted to participants in their local dialect (Hausa language) and assisted in completing them. Each questionnaire was assigned a number that corresponds to the number assigned to participant's stool sample collected.

\section{Data analysis}

Data generated were analyzed using statistical package for social scientist (SPSS) version 20. Descriptive statistics was used to present frequency distribution, and prevalence of $S$. mansoni. Chi-square test, analysis of variance and correlation analysis were used to test association between Body Mass Index and $\mathcal{S}$. mansoni infection.

\section{Results}

Out of the 360 stool samples examined for $S$. mansoni eggs, 67 (18.61\%) were found to be positive as shown in Table 1 . The table also shows the prevalence of $S$. mansoni infection among the different schools surveyed. Although the schools are all located in the same district (Kawo), there is a significant difference in prevalence of intestinal schistosomiasis among the participants from these schools $(\mathrm{P}<0.05)$. 
Citation: Mohammed M, Vantsawa PA, Abdullahi UY, Muktar MD (2015) Nutritional Status and Prevalence of Intestinal Schistosomiasis among Al-majiri Population in Kawo District of Kaduna Metropolis, Kaduna State-Nigeria. J Bacteriol Parasitol 6: 237. doi: 10.4172/2155-9597.1000237

Page 3 of 5

The age related prevalence of $S$. mansoni among the different age groups of Al-Majiri that participated in the study is presented in Table 2. No significant difference was found between age groups in relation to schistosome infection in kawo district. The highest prevalence was found among 20-24 yrs age group, followed by 10-14 yrs, 5-9 yrs and $15-19 y$ yrs age groups with prevalence of $28.57 \%, 23.0 \%, 13.16 \%$ and $10.77 \%$ respectively. The intensity which is indicated by the mean fecal egg count however was highest in 10-14 yr age group with 74 epg followed by 5-9 yr group with $63 \mathrm{epg}$ of stool sample. Relatively lower egg counts were recorded for 15-19 and 20-24 yr age groups.

\begin{tabular}{|l|l|l|l|}
\hline School & No. examine & No. infected & $\begin{array}{l}\text { Percentage } \\
\text { infected }\end{array}$ \\
\hline ASKK-1 & 69 & 05 & 7.25 \\
\hline ASKK-2 & 31 & 01 & 3.23 \\
\hline ASKK-3 & 75 & 16 & 21.33 \\
\hline ASKK-4 & 83 & 20 & 24.09 \\
\hline ASBK-5 & 102 & 25 & 24.5 \\
\hline Total & 360 & 67 & 18.61 \\
\hline
\end{tabular}

Chi-square=15.1; $\quad$ DF=4; Probability=0.005; ASKK: Almajiri School Kawo Kaduna; ASBK: Almajiri School Badarawa Kaduna

Table 1: Distribution of $S$. mansoni infection among different Almajiri schools in Kawo district of Kaduna Metropolis, Kaduna State, Nigeria.

Table 3 shows stream-contact related prevalence of $S$. mansoni among the Al-Majiri population surveyed. The prevalence among those engage in different water related activities shows a significant difference $(\mathrm{P}<0.05)$ with participants engaged in washing using stream as their major source of water recording the highest prevalence of $40 \%$. Participants engaged in irrigation farming (either as paid labor or unpaid labor) and bathing had prevalence of $1.9 \%$ and $17.1 \%$ respectively. The least prevalence was recorded among participants who use stream as their main source of drinking water.

\begin{tabular}{|l|l|l|l|l|}
\hline $\begin{array}{l}\text { Age group } \\
\text { (years) }\end{array}$ & $\begin{array}{l}\text { Number } \\
\text { examined }\end{array}$ & $\begin{array}{l}\text { Number } \\
\text { infected }\end{array}$ & $\begin{array}{l}\text { Percentage (\%) } \\
\text { infected }\end{array}$ & Mean epg \\
\hline $5-9$ & 76 & 10 & 13.16 & 63.00 \\
\hline $10-14$ & 209 & 48 & 23.00 & 74.12 \\
\hline $15-19$ & 65 & 7 & 10.77 & 38.00 \\
\hline $20-24$ & 7 & 2 & 28.57 & 26.00 \\
\hline Above 25 & 3 & 0 & 0.00 & 0.00 \\
\hline Total & 360 & 67 & 18.61 & 40.00 \\
\hline Chi-square=7.89; DF=4; Probability=0.005 & &
\end{tabular}

Table 2: Age related prevalence among sampled Al-Majiri population in Kawo district of Kaduna metropolis, Kaduna State Nigeria.

The perception of the studied population on the causes of schistosomiasis is shown in Table 4. About 30.8\% believed that schistosomiasis is caused by yellow fever, $26.4 \%$ by pile, and $12.8 \%$ by food poisoning while only $7.5 \%$ associated the infection to water contact activities.

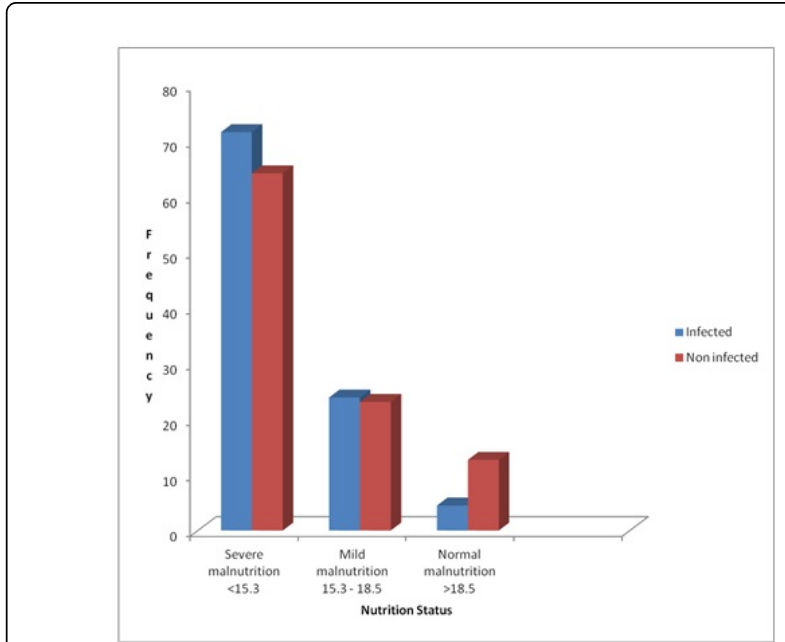

Figure 2: Nutrition Status based on body mass index (BMI) of infected and non-infected Al-majiri population in Kawo district, Kaduna State, Nigeria.

\begin{tabular}{|l|l|l|l|}
\hline $\begin{array}{l}\text { Purpose of water } \\
\text { usage. }\end{array}$ & $\begin{array}{l}\text { Number } \\
\text { examined }\end{array}$ & $\begin{array}{l}\text { Number } \\
\text { infected }\end{array}$ & $\begin{array}{l}\text { Occurrence rate } \\
(\%)\end{array}$ \\
\hline Washing & 50 & 20 & 40 \\
\hline Bathing & 70 & 12 & 17.1 \\
\hline Drinking & 11 & 1 & 9.1 \\
\hline Irrigation & 117 & 21 & 17.9 \\
\hline Fishing & 80 & 8 & 10 \\
\hline Wading & 32 & 5 & 15.6 \\
\hline Total & 360 & 67 & 42.1 \\
\hline Chi-square=20.0; DF=5; Probability=0.001 & \\
\hline
\end{tabular}

Table 3: Stream contact-related prevalence of S. mansoni among sampled Al-Majiri population in Kawo-district, Kaduna metropolis, Kaduna State - Nigeria.

\begin{tabular}{|l|l|}
\hline Attributable cause of schistosomiasis & No. of respondents (\%) \\
\hline Yellow fever & $112(30.8)$ \\
\hline Water borne & $27(7.5)$ \\
\hline Malaria & $42(11.7)$ \\
\hline Evil spirit & $38(10.6)$ \\
\hline Pile & $95(26.4)$ \\
\hline Food poisoning & $46(12.8)$ \\
\hline Total & $360(100)$ \\
\hline
\end{tabular}

Table 4: Perception of sampled Al-Majiri population in Kawo district on the causes of schistosomiasis. 
Citation: Mohammed M, Vantsawa PA, Abdullahi UY, Muktar MD (2015) Nutritional Status and Prevalence of Intestinal Schistosomiasis among Al-majiri Population in Kawo District of Kaduna Metropolis, Kaduna State-Nigeria. J Bacteriol Parasitol 6: 237. doi: 10.4172/2155-9597.1000237

Page 4 of 5

The relationship between $S$. mansoni infection and the nutritional status of Al-Majiri population based on body mass index (BMI) is presented in Figure 2. There is an inverse correlation $(\mathrm{r}=-0.999)$ between malnutrition and $S$. mansoni infection among the participants.

\section{Discussion}

The distribution of $S$. mansoni infection among different Al-Majiri schools showed that schistosomiasis is prevalent in the district. Umar [12] reported high prevalence of urinary schistosomiasis among primary school pupils in Kaduna metropolis, Kaduna state. The prevalence recorded among the Al-Majiri population therefore is an indication of the vulnerability of this segment of the population to soil and water borne diseases due to continuous exposure to contaminated environment, poor nutrition and hygiene practice. The prevalence of $18.61 \%$ recorded in this study is of public health significance considering the mean egg count (epg) recorded among infected participants who could serve as continuous source of environmental contamination.

The age related increase in prevalence recorded in this study agrees with the reports of Nanvya et al. [13], Sawole and Adegbite [14] and Timothy et al. [15] who observed increased prevalence in persons within the first decade of life. The authors associated the increase prevalence with age as a result of frequent contact with water source since they handle must domestic activities like washing and fetching water while some of them take the liberty of bathing in such water which may be contaminated with trematode cercaria. However, the low intensity of $S$. mansoni infection as reflected by the mean epg in age groups greater than 14 years might be due to age related immunity commonly exhibited by human host in many parasitic infections including schistosomiasis. The immunity in older individuals is usually associated with decreased egg output by female parasite thus explaining the negative result obtained in this age group.

Water related activities such as bathing, swimming, irrigation among others are reported to enhance the risk of schistosome infection [16,17]. The high prevalence of $S$. mansoni recorded among Al-Majiri who are engaged in irrigation farming, bathing and washing therefore is to be expected. Most of the streams within the district where such activities take place often serve as intakes of domestic waste from houses; such wastes may contain both sewage and other household waste, thus contaminating such water bodies. Umar and Adamu reported high contamination of vegetables with helminth eggs and cyst from fadama farms that were irrigated with water from streams within Kaduna metropolis [18].

The association between parasitic infection and malnutrition has been reported [19]. Parasites are known to depend on their host for nutrients and in the process deprive the host of essential nutrient needed for growth and development. The inverse relationship observed between body mass index (BMI) and intestinal schistosomiasis is therefore not surprising. BMI which is a measure of malnutrition reflected severe malnutrition in Almiji children infected with intestinal schistosomiasis. Although $S$. mansoni may not directly interfere with intestinal absorption as in most intestinal helminthosis, as a blood fluke it causes iron deficiency anaemia through intestinal blood loss which could result in reduced amount of blood available to transport nutrient to all body organs [20-22].

The poor perception (92.5\%) of the participants on the possible causes of schistosomiasis is a reflection of the level of awareness of the disease by the wider community. This poor awareness therefore could be associated with failure of relevant government agency and NonGovernmental Organizations (NGOs) to carry out enlightenment campaigns at the community level where the population are most vulnerable to most of the neglected parasitic infections such as schistosomiasis.

\section{Conclusion/Recommendation}

The prevalence of intestinal schistosomiasis among the Al-majiri population studied is high and most of the infected participants were malnourished as indicated by the BMI index for age. In addition, the level of awareness on the possible causes of schistosomiasis by the communities in Kawo district is low as reflected by over $90 \%$ of the participants. This poor perception of schistosomiasis by this segment of the population could be a hindrance to schistosomiasis control in the state and the nation at large. Hence the need for stakeholder and relevant government health agencies to come to the aid of these less privileged and vulnerable group by educating them on the mode of transmission of schistosomiasis, providing them with rich but relatively cost effective feeding regime and administering free treatment to those infected through a mass treatment program.

\section{References}

1. Hudu AS, Abdulgafar OJ (2011) Assessment of socio-economic, demographic and health problems of Al-Majiri in Sokoto state, NorthWestern Nigeria. Internal Journal tropical Medicine 6: 58-60.

2. WHO (2013) World Health Organization Fact sheet. Schistosomiasis.

3. Grácio MA, Rollinson D, Costa C, Nhaque AT (1992) Intestinal schistosomiasis report of the first cases in Guinea Bissau. Trans R Soc Trop Med Hyg 86: 183.

4. Ogbe MG (2002) Schistosomiasis (Bilharziasis): An ancient water borne disease that occurs in some of our communities. The Zoologist 1: 91-104.

5. WHO (2010) World Health Organization Fact sheet. Schistosomiasis.

6. Arora DR, Arora B (2005) Medical Parasitology (2ndedn.) CBS Publishers and Distributors, New Delhi. Indian Journal of Medical Microbiology 23: 71.

7. Hassard T (1991) Understanding Biostatics (2ndedn.) Mosby Year Book Inc., St. Louis, pp. 38-61.

8. Cheesbrough M (2009) District laboratory practice in tropical countries. Cambridge University Press, London, pp. 196-197.

9. WHO (1995) Physical status: the use and interpretation of anthropometry. WHO Technical report No 854, Geneva.

10. Moussa S, Pascal M, Adama DK, Magnussen ST, Aly L, et al. (2011) Impact of Schistosoma haematobium infection on urinary tract pathology, nutritional status and anaemia in school aged children in two different endemic areas of Niger River basin, Mali. Journal acta tropica 120: S142-S150.

11. CDC (2012) Anthropometric reference Data for children and adults, United State 2007-2010. DHHS Publication, pp. 1-2.

12. Umar YA (2009) Prevalence of urinary schistosomiasis among primary school pupils in Kaduna metropolis, Kaduna state, Nigeria. Research journal of science 16: 65-71.

13. Nanvya TN, Dakull DA, Mwansat GS (2011) Schistosomiasis in Ndijor district of lantang north local government area of plateau state, Nigeria. Journal of Parasitology 32: 209-213.

14. Sawole AR, Adegbite AA (2012) Correlation analysis between the prevalence of Schistosoma haematobium and water conditions: a case study among school pupils of southern Nigeria. IJRRAS 13: 160-165.

15. Timothy A, Ezekiel K, Oricha KA (2013) Studies on the intestinal Helminth infestation among primary school children in Gwagwada, 
Citation: Mohammed M, Vantsawa PA, Abdullahi UY, Muktar MD (2015) Nutritional Status and Prevalence of Intestinal Schistosomiasis among Al-majiri Population in Kawo District of Kaduna Metropolis, Kaduna State-Nigeria. J Bacteriol Parasitol 6: 237. doi: 10.4172/2155-9597.1000237

Page 5 of 5

Kaduna, North Western Nigeria. Journal of Biology Agriculture and Healthcare 7: 48-53.

16. Houmsou RS, Amuta EU, Sari T (2012) Profile of epidemiological study of urinary schistosomiasis in two local government areas of Benue state, Nigeria. International Journal of Medicine and Biomedical Research 1: 39-48.

17. Bala AY, Ladan MU, Mainasara M (2012) Prevalence and intensity of urinary Schistosomiasis in Abarma village, Gusau, Nigeria: a preliminary investigation. Science World Journal 7: 1-4.

18. Umar YA, Adamu NB (2004) Survey of helminth eggs on some selected vegetables sold in Kaduna markets, Kaduna state Nigeria. West African Journal of Biological sciences 15: 45-47.
19. Raheem S, Ayemi JO, Fashedemi AO (2014) Easing the 'Disease' of poverty in Nigeria. Journal of Developing country studies 4: 155-166.

20. Friedman JF, Kanzaria HK, McGarvey ST (2005) Human schistosomiasis and anemia: the relationship and potential mechanisms. Trends Parasitol 21: 386-392.

21. Shaw JG, Friedman JF (2011) Iron Deficiency Anemia: Focus on Infectious Diseases in Lesser Developed Countries. Anemia 2011: 10p.

22. Hotez PJ, Kamanth A (2009) Neglected tropical diseases in Sub-Saharan Africa: review of their prevalence, distribution and disease burden. PLoS Negl Trop Dis 3: e412. 